\title{
New Developments in Mechanical Enhancement of Colonoscopy: Cuffs, Caps and Rings
}

\author{
Deepanshu Jain $^{\text {a }}$ Naemat Sandhu $^{\text {a }}$ Shashideep Singhal ${ }^{b}$ \\ ${ }^{a}$ Department of Internal Medicine, Albert Einstein Medical Center, Philadelphia, Pa., and ${ }^{\mathrm{b}}$ Division of \\ Gastroenterology, Hepatology and Nutrition, University of Texas Health Science Center at Houston, \\ Houston, Tex., USA
}

\author{
Key Words \\ Endocuff colonoscopy - Cap-assisted colonoscopy . \\ Endorings colonoscopy - Adenoma detection rate . \\ Cecum intubation rate
}

incomplete colonoscopy and increase overall patient satisfaction, thus improving follow-up. In the absence of any additional adverse events, EC, CAC and ERC have potential to enhance the benefits of colonoscopy. @ $\quad 016 \mathrm{~S}$. Karger AG, Basel

\begin{abstract}
Background: Colorectal cancer (CRC) is a common cause of cancer-related deaths. Early detection of precursor lesions in the adenoma-carcinoma sequence via colonoscopy can decrease mortality from CRC. Summary: In this review article, we have summarized retrospective studies, prospective single center, multicenter studies and randomized controlled trials describing the efficacy of endocuff colonoscopy (EC), cap-assisted colonoscopy (CAC) and endorings colonoscopy (ERC). Indications, techniques, outcomes, limitations and complications reported are discussed. Key Message: Use of colonoscope with cap, cuff or rings attached to its distal tip has been shown to increase the polyp detection rate and adenoma detection rate, predominantly for the small polyps $(<1 \mathrm{~cm})$ and proximal colon location. Evidence is uniform for EC and ERC but not for CAC. Benefits of shorter cecum intubation time, improved cecum intubation rates and decreased pain scores during colonoscopy done with assistance of cuff or cap has potential to decrease the number of
\end{abstract}

\section{Introduction}

Approximately, 132,700 new cases of colorectal cancer (CRC) will be diagnosed in 2015 . It will constitute $8 \%$ of newly diagnosed cancers in the United States (US). It is the second leading cause of death from cancer with 49,700 estimated deaths in 2015 in the US [1]. Most of the CRCs follow the adenoma-carcinoma sequence of progression. Hence, removal of adenoma lowers the incidence of colon cancer-related death [2-4].

Colonoscopy is a standard for primary and follow-up screening for detection of CRC [5]. The adenoma detection rate $(\mathrm{ADR})$ is an independent factor for prediction of risk of interval CRC after a screening colonoscopy [6]. Reason for missing a lesion during colonoscopy can be either patient related or endoscopist dependent. Newer techniques like cap-assisted colonoscopy (CAC) or endocuff- or endoring-assisted colonoscopy helps the physi-

\section{KARGER}

E-Mail karger@karger.com www.karger.com/dig
(C) 2016 S. Karger AG, Basel

$0012-2823 / 16 / 0933-0234 \$ 39.50 / 0$
Shashideep Singhal, MD

Division of Gastroenterology, Hepatology and Nutrition University of Texas Health Science Center at Houston 6431 Fannin, MSB 4.234, Houston, TX 77030 (USA)

E-Mail sdsinghal@gmail.com 
cian to look behind the colon mucosal folds, which are notorious in hiding the culprit lesions. Better and complete visualization of the colon mucosa leads to improvement in ADR and thus, has the potential to reduce the incidence of interval CRC.

In this review article, we have summarized retrospective studies, prospective single center, multicenter studies and randomized controlled trials (RCTs) describing the efficacy of CAC or endocuff colonoscopy (EC) or endorings colonoscopy (ERC). Indications, techniques, outcomes, limitations and complications reported are discussed.

\section{Materials and Methods}

An extensive English language literature search was done till July 2015 using PubMed, Medline and Google to identify the peerreviewed original and review articles using the following key words: EC, CAC, ERC and ADR. Endocuff is no longer available in the market and has been replaced by endovision. But for the purpose of our article, we have used the term 'endocuff to avoid any confusion. Only human study subject articles were selected. The references of pertinent studies were manually searched to identify additional relevant studies. The inclusion criteria, device details, procedural details, technical success rates, clinical outcomes primarily ADRs, complications and limitations were reviewed.

\section{Results}

Eleven original articles were considered appropriate to be included in this review article. Three studies including 2 prospective RCTs $[7,8]$ and 1 retrospective study [9], all from Germany describing the EC were included for the review. Six prospective RCTs, 1 each from Germany [10], Hong Kong [11], Netherlands [12], US [13], South Korea [14], Australia [15] and 1 retrospective study from Hong Kong [16] describing the CAC were included for the review. One multicenter (Netherlands, Israel and US) RCT describing ERC was also included [17]. All studies have been summarized in table 1 .

\section{Discussion}

\section{Indication}

The studies included patients above the age of 18 years, who were able to give an informed consent. They included patients undergoing screening, surveillance and diagnostic colonoscopies [7-17]. Diagnostic colonoscopies included, but were not limited to symptoms of abdominal pain and evaluation of anemia [7-9]. Regular colonoscopies with technical difficulty in polyp resection [14] or failure of cecum intubation [16] were also included.

Patients who had a prior history of or known colonic strictures, tumors, colorectal surgery, partial colonic resection, extensive diverticulosis, acute diverticulitis within 6 weeks of examination, suspected or proven acute lower gastrointestinal bleeding, history of chronic inflammatory bowel disease or familial adenomatous polyposis, end-stage disease including congestive heart failure and renal insufficiency, coagulopathy which included platelet count of $<50,000$, physical deconditioning, anticoagulant or anti-platelet use and inadequate bowel preparation were excluded by the respective authors [7-17]. Few authors used additional exclusion criteria like prior colonoscopy [11] or a full colonic examination within 5 years of enrollment in study.

\section{Type of Colonoscopy and Technical Aspect}

In the prospective studies, the study subjects were grouped into 2 arms based on the type of intervention: EC [7-9] or CAC [10-15] or ERC [17] versus standard colonoscopy (SC), regular colonoscopy (RC) or conventional colonoscopy (CC). The retrospective studies looked into the EC [9] and CAC [16] performed. All technical details of the colonoscopy have been detailed in online supplementary table 1 (for all online suppl. material, see www. karger.com/doi/10.1159/000445108).

\section{Colonoscope and Its Accessories}

Endocuff consists of columns of flexible arms which pivot at their base to assist in achieving cecum intubation, keeps mucosa away from the visual lens and keeps the tip of colonoscope steady during any intervention (fig. 1a and b). Floer et al. [7] used Fujifilm endoscope (EC-590 WM4/WL4) and Olympus colonoscope (CF-H180 AI/ $\mathrm{AL}$ ) for both EC and SC. The device mounted on the tip of the endoscopes for EC was AEC 120 for Fujifilm scopes and AEC 140 for the Olympus scopes. The same model of colonoscopies and devices for EC were used by Biecker et al. [8].

Cap essentially is a transparent plastic hood attached to the tip of colonoscope which flattens mucosal folds and improves the visual field during colonoscopy (fig. 2a and b). Frieling et al. [10] used conventional video Fujionon colonoscope for both CAC and CC. For the CAC, the colonoscope was attached with a conventional transparent mucosectomy cap of the Olympus D201 series [10]. Suction and insufflation of air through the endoscope was 


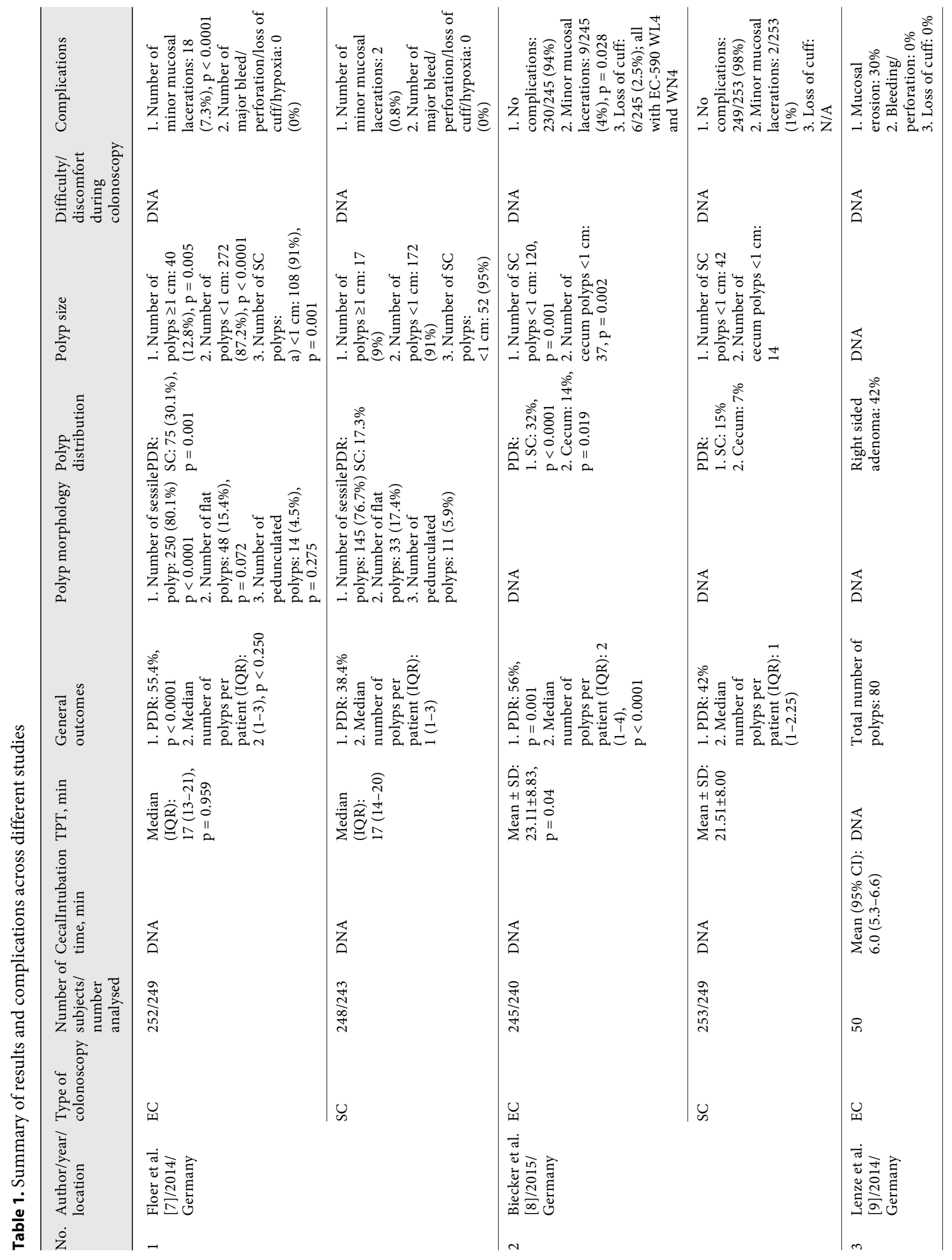




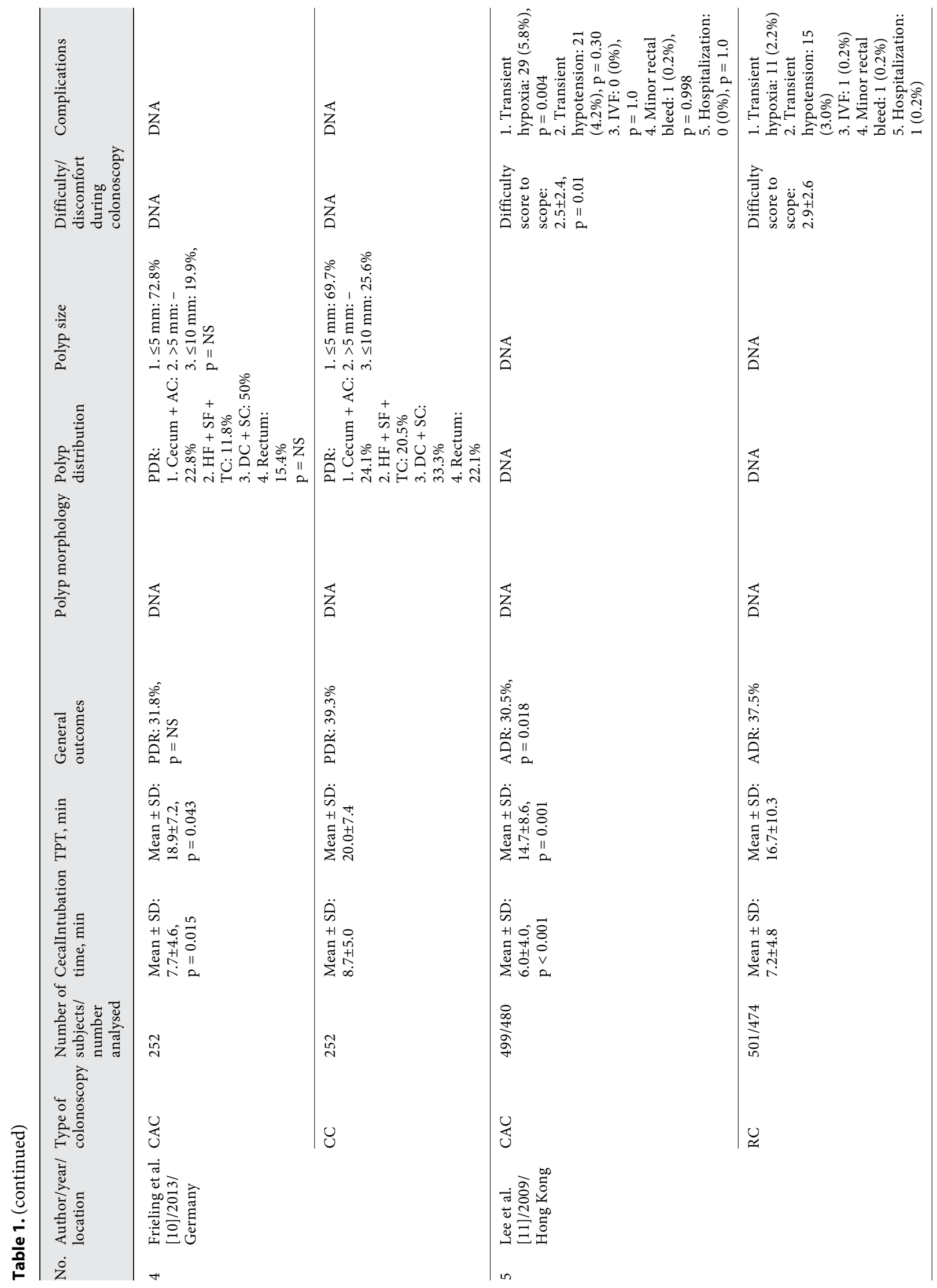




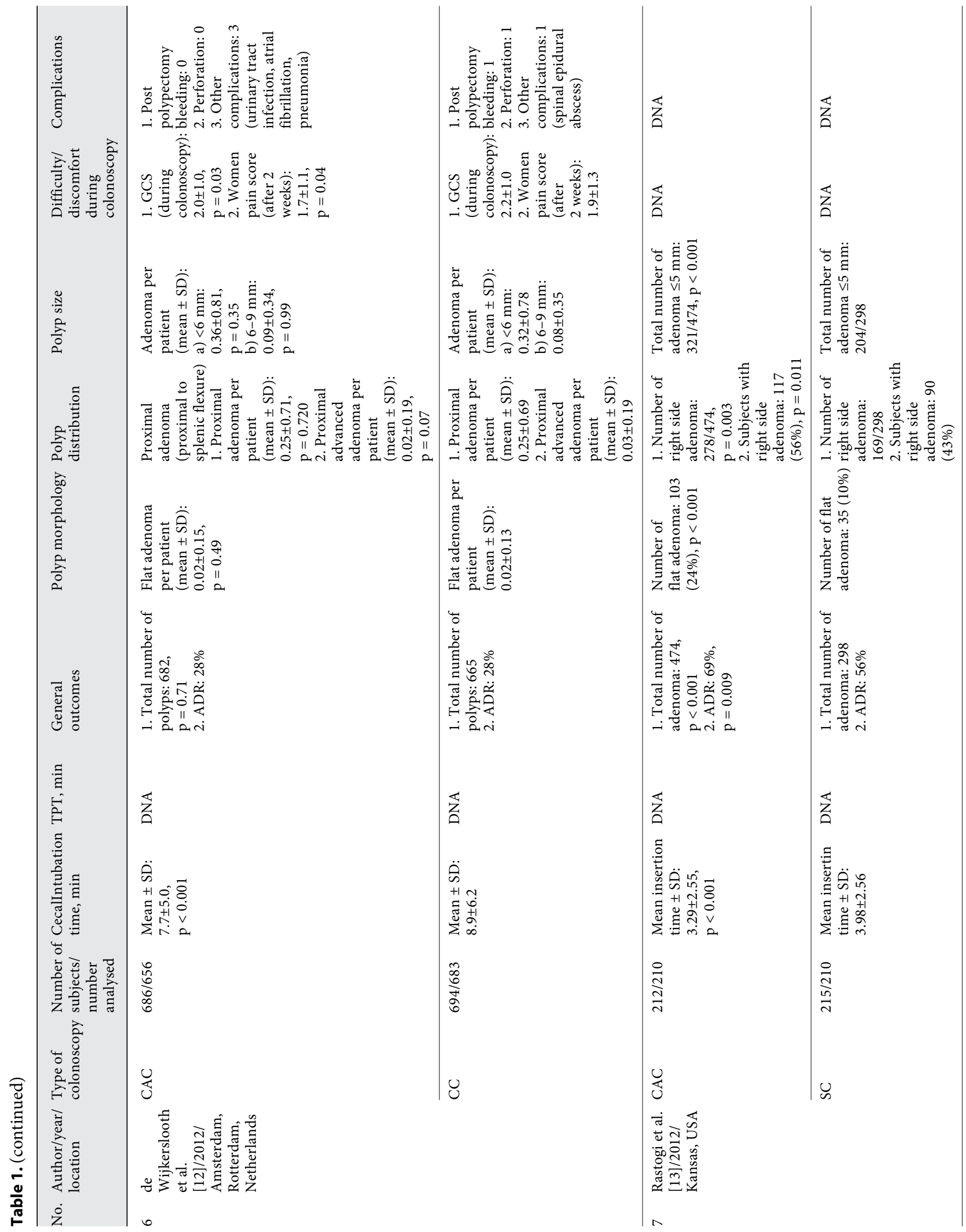




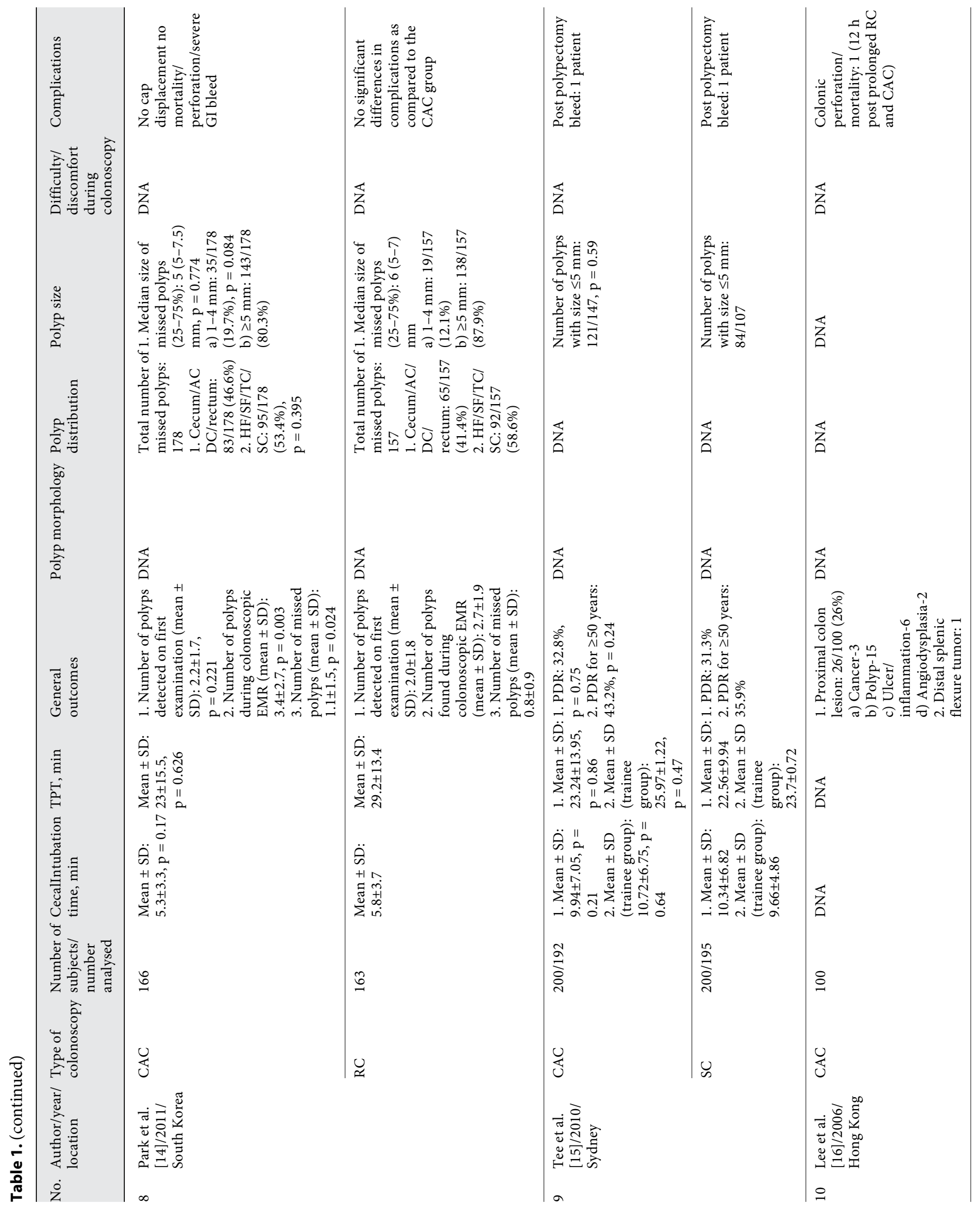




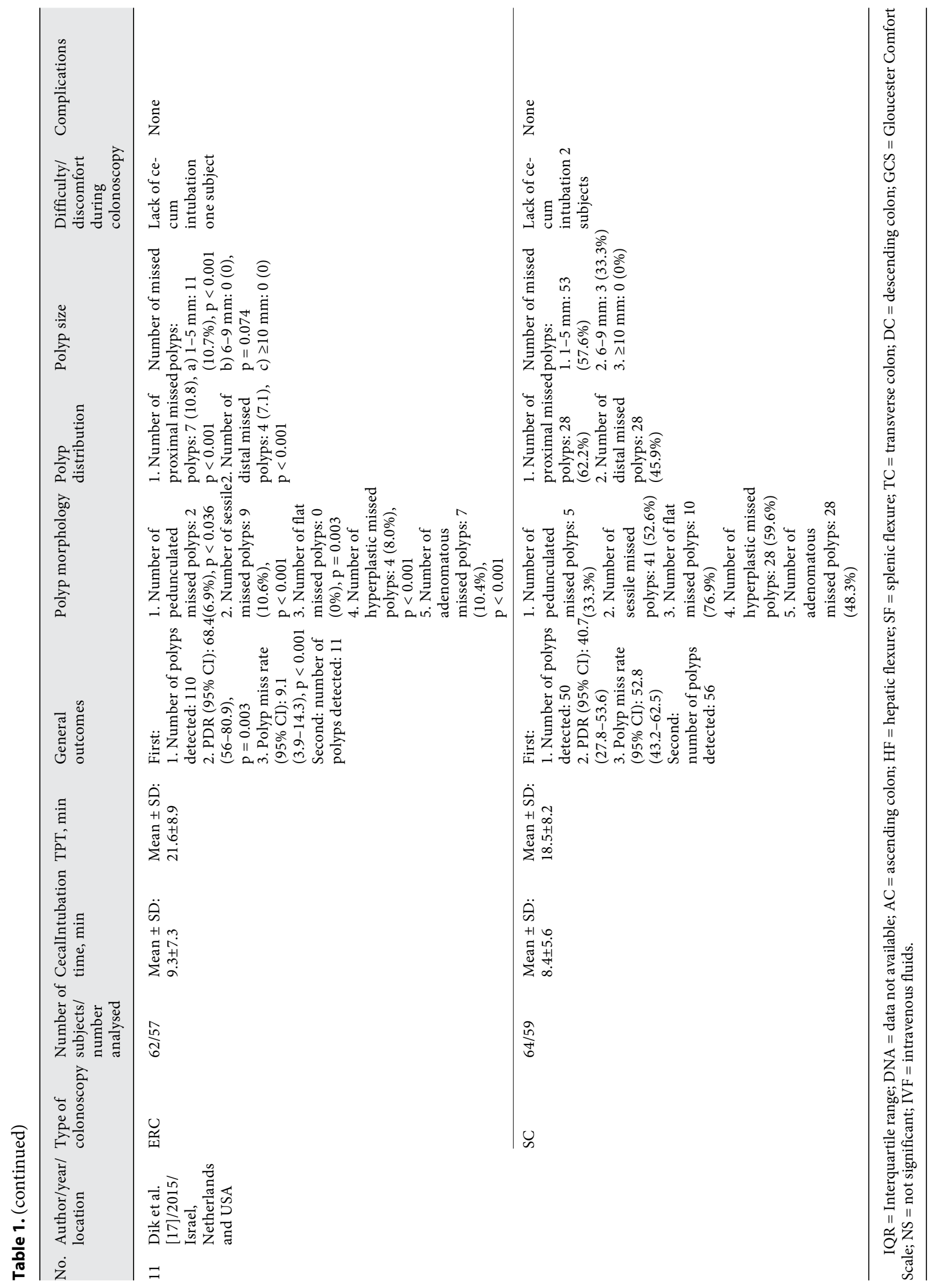




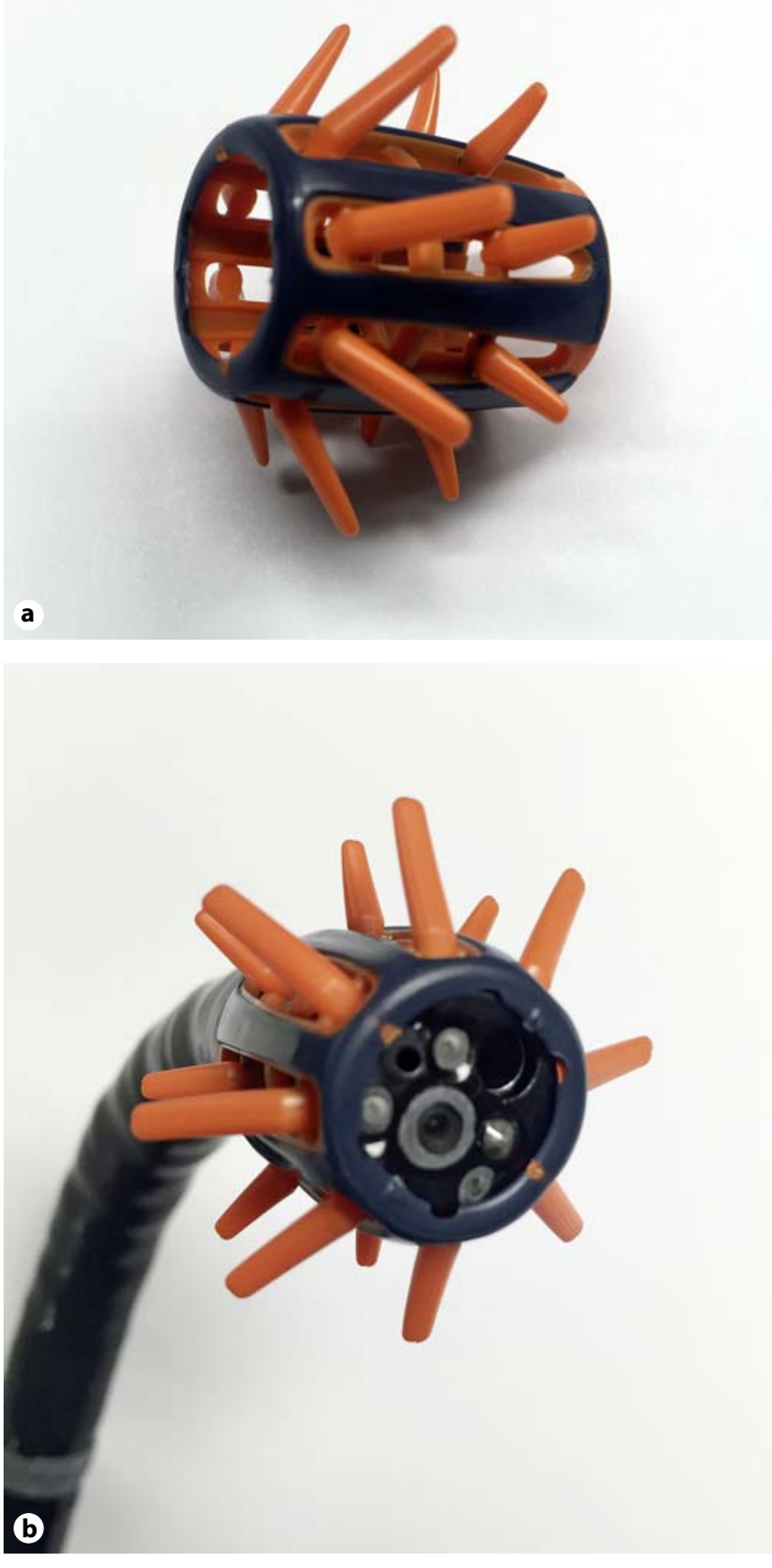

Fig. 1. a Cuff; b cuff attached to colonoscope.

not affected by the cap used, which were $5-10 \mathrm{~mm}$ in length. Olympus series of endoscopes and mucosectomy caps were used in the remaining studies [11-15]. There was no reported limitation in the field of view for the endoscopist upon addition of the transparent cap to the colonoscope.

Cuffs, Caps and Rings in Enhancing Colonoscopy Outcome
Endorings are flexible silicone rings that are attached in 3 circular rows around the distal end of the colonoscope. They improve visualization of colon mucosa by mechanically straightening colonic folds during withdrawal and by keeping the tip of colonoscope in the center of lumen (fig. 3; reproduced with permission from Thieme publications, license No. 3814950612408). In the CLEVER study, author used Olympus or Pentax colonoscope with endoring attached to its distal tip [17].

Details of the colonoscopes used in the retrospective studies by Lenze et al. [9] and Lee et al. [16] were not available.

\section{Endoscopist Experience}

All colonoscopies (EC, CAP, ERC, SC) were performed by board certified gastroenterologists, except for the study conducted by Lee et al. [16] where gastroenterology fellow with 1 year experience conducted the colonoscopies under direct supervision and by Tee et al. [15] where in addition to consultant gastroenterologists, 10 trainees were also performing the colonoscopies [7-17]. The endoscopists had considerable amount of experience performing colonoscopies with some having performed up to 3,000 colonoscopies. Three studies specifically trained the colonoscopists to perform EC or CAC before enrolling the patients for the study $[7,12,13]$. Colonoscopies performed by trainees under Tee et al. [15], had no significant differences in the total procedure time (TPT), cecum intubation rate and time as compared to those done by expert gastroenterologist.

\section{Bowel Preparation and Quality}

Majority of the studies used MoviPrep or polyethylene glycol for colon cleansing $[7,8,10-12,14,17]$. Prior to the prep, subjects in Frieling et al. [10], Lee et al. [11] and Park et al. [14] were on a 3-day low residue diet and then given 4 liters of MoviPrep or $90 \mathrm{ml}$ of phospho soda [10,11]. Tee et al. [15] used a 1-day clear diet, sodium phosphate or picosulfate-based prep with $8 \mathrm{~h}$ of fasting. The quality of bowel prep was categorized as excellent, good, fair and poor. However, clear-cut indicators were not defined uniformly. Different scoring systems were utilized by authors to interpret bowel preparation quality. de Wijkerslooth et al. [12] utilized the Ottawa score for this purpose whereas Boston bowel preparation score was used in the CLEVER study [17]. The percentage of subjects with poor bowel prep varied from 5 to $13.8 \%$, the highest being in the CAC group of Lee et al. [11] Poor bowel quality was reported in $13.8 \%$ of CAC group as compared to $9.6 \%$ of RC group [11]. This was one of the possible factors for 

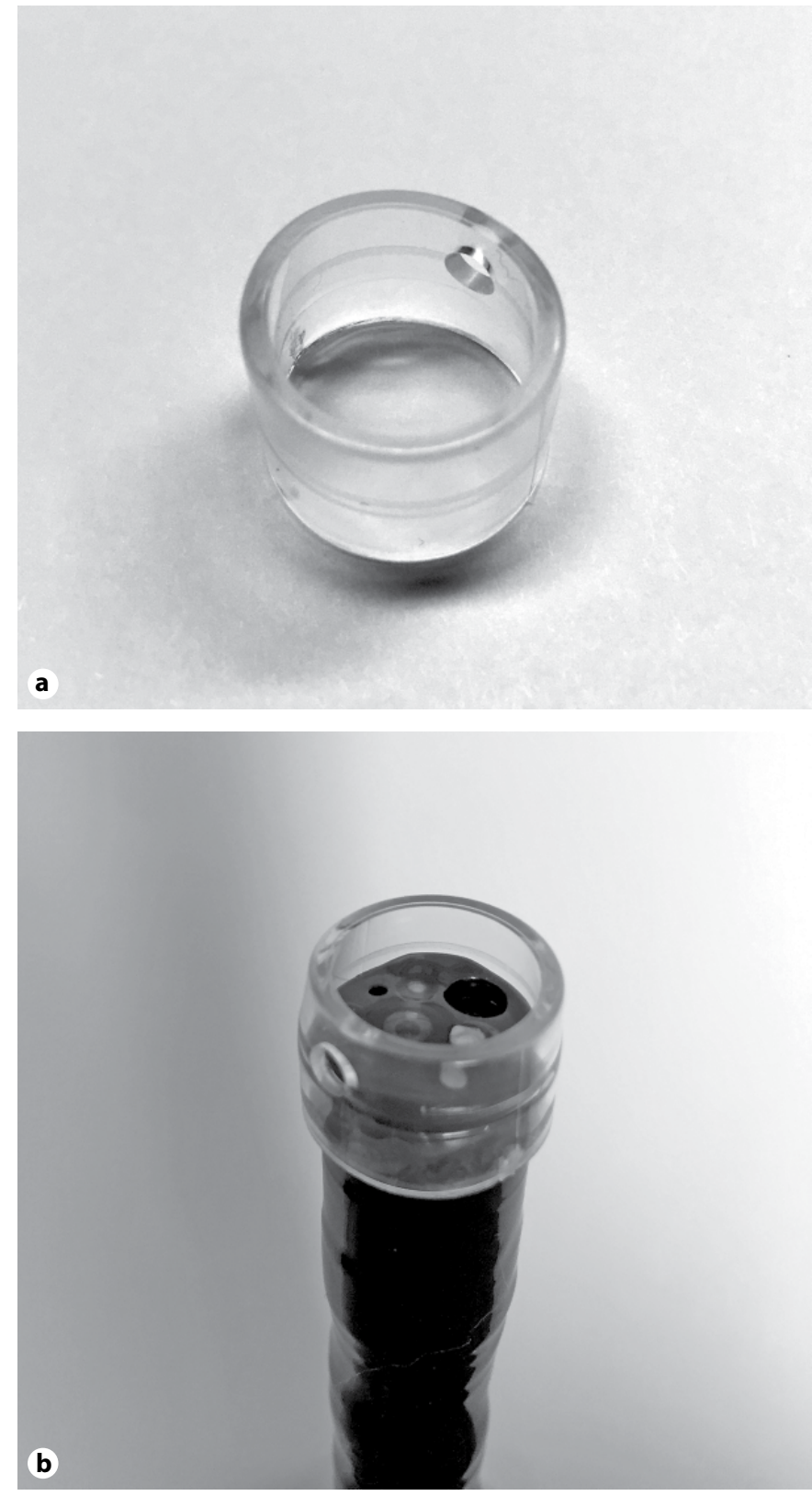

Fig. 2. a Cap; b cap attached to colonoscope.

lower ADR in the CAC group of their study, details of which will be discussed in subsequent sections of this article.

\section{Procedural Characteristics}

Summary of the procedural characteristics including anesthesia details, cecum intubation rate, cecum intubation time (CIT), ileum intubation rate and time, procedure time and net withdrawal time have been detailed in online supplementary table 1 .

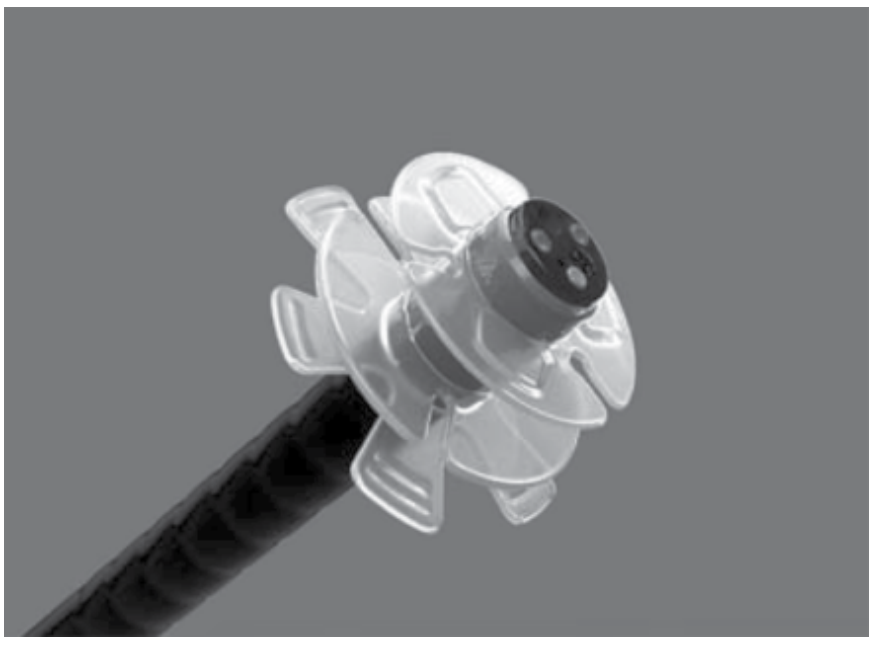

Fig. 3. Endorings attached to colonoscope (reproduced with permission from Thieme publications, license No. 3814950612408).

\section{Anesthetic and Analgesic Agents}

All prospective studies reviewed in the article used conscious sedation. Floer et al. [7] and Biecker et al. [8] both used intervenous (IV) propofol with a PRN dose along with fentanyl for achieving conscious sedation. Frieling et al. [10] utilized $20 \mathrm{mg}$ of IV propofol and $1.5 \mathrm{mg}$ of IV midazolam. Diazepam at the dose of $0.05 \mathrm{mg} / \mathrm{kg}$ was the primary agent used by Lee et al. [11] with use of pethidine as needed. The mean dose of diazepam used in both $\mathrm{CAC}$ and $\mathrm{RC}$ was $2.6 \mathrm{mg}( \pm 2.6)$. Midazolam and fentanyl were used in 4 studies [13-15, 17]. Other agents like meperidine [14], propofol [15] and hyoscine butylbromide [15] as an antispasmodic were also used. All studies discussed above showed no significant differences in the dose of anesthetic and analgesic needed between the 2 groups of colonoscopies except for Floer et al. [7], where a median dose of $150 \mathrm{mg}$ of propofol was used in the EC subgroup versus $170 \mathrm{mg}$ in the SC subgroup which was statistically significant.

\section{Cecum Intubation Rate and Time}

For many studies, the primary end point was defined by a successful cecum intubation and the time taken to reach the cecum floor from the anus. Cecum intubation has been defined as one of the quality indicator for a screening colonoscopy. Barring a few studies where the cecum intubation rate was not reported $[8,14]$, the rate of successful cecum intubation was comparable across the 2 arms for most of the studies [7, 9-13, 15-17]. In the study by Tee et al. [15], the rate of cecum intubation was comparable between the $\mathrm{CAC}$ and $\mathrm{SC}$ group when per- 
formed by the consultants and trainees within the same endoscopist groups. However, the intubation rate was $88.1 \%$ in the CAC performed by trainees and $96 \%$ in CAC by consultants. Similarly, in SC performed by trainees, the rate was $84.8 \%$ as compared to $97 \%$ when performed by consultants. This may be reflective of the experience of the endoscopist. All other studies had a cecum intubation rate of $>90 \%[7,9,12,13,15-17]$, reaching up to $100 \%$ in both groups in the study by Frieling et al. [10].

None of the studies describing the EC reported CIT in comparison to SC arm $[7,8]$. In the retrospective study, mean CIT for EC group was reported to be $6.0 \mathrm{~min}$, but there was no control arm [9].

In the prospective study conducted by Frieling et al. [10], the mean time to reach the cecum floor was significantly lower in the CAC group as compared to the SC group. The mean time for cecum intubation was $7.7 \pm 4.6$ min in CAC versus $8.7 \pm 5.0 \mathrm{~min}$ in SC. Similar trend was demonstrated by Lee et al. [11], with $6.0 \pm 4.0 \mathrm{~min}$ required to reach the cecum floor in the CAC arm when compared to $7.2 \pm 4.8 \mathrm{~min}$ in the $\mathrm{RC}$ arm. de Wijkerslooth et al. [12] demonstrated that in CAC group the endoscopists were able to achieve cecum intubation $1.2 \mathrm{~min}$ faster than the CC group. Rastogi et al. [13] reported a lower mean CIT for the CAC group $(3.29 \pm 2.55 \mathrm{~min})$ in comparison to the $\mathrm{SC}$ group $(3.98 \pm 2.56 \mathrm{~min})$. Faster cecum intubation with CAC is the result of easier motion of the colonoscope to slide along the folds and flexures in the colon as a result of the protruding transparent cap which allows the scope to be advanced faster. In the RCT performed by Park et al. [14] the 2 groups, CAC and RC, had almost similar mean CIT (5.3 \pm 3.3 and $5.8 \pm 3.7 \mathrm{~min}$, respectively). There was no significant difference in CIT across consultants and trainees in the study by Tee et al. [15].

Higher mean CIT was reported for the ERC study arm $(9.3 \pm 7.3 \mathrm{~min})$ as compared to the SC $(8.4 \pm 5.6 \mathrm{~min})$ but the difference was minimal and it lacked statistical significance $(\mathrm{p}=0.142)$ [17].

It is safe to conclude that CIT is likely to be reduced with use of CAC when compared to SC. There is insufficient data to support the same for EC or ERC groups. The cecum intubation rate was comparable for EC or CAC or ERC against SC.

Total Procedure Time

Biecker et al. [8] in their prospective study reported a 1.5 min prolongation of the mean TPT for the EC group $(23.1 \pm 8.8 \mathrm{~min})$ in comparison to SC group $(21.5 \pm 8.0$ $\mathrm{min}$ ) which was statistically significant. TPT across EC and SC groups was comparable in the study by Floer et al. [7].
Interestingly, TPT was lower for the CAC group in studies performed by Frieling et al. [10] and Lee et al. [11]. There was a $1.1 \mathrm{~min}$ decrease in mean TPT for CAC group $(18.9 \pm 7.2 \mathrm{~min})$ as compared to the CC group $(20.0 \pm 7.4$ min) [10]. Similarly, mean TPT for the CAC group (14.7 \pm $8.6 \mathrm{~min})$ was $2 \mathrm{~min}$ lower than that of RC group (16.7 \pm $10.3 \mathrm{~min}$ ) [11]. TPT was comparable across the study arms in other CAC studies $[14,15]$.

TPT for ERC group was $3 \mathrm{~min}$ more than that for SC group ( $p=0.001)$, but author attributed this to extra time spent over removal of increased number of polyps detected by ERC $(3.5 \pm 4.3)$ as compared to SC $(1.8 \pm 4.5 ; \mathrm{p}=0.001)$ [17]. Also, time spent per polypectomy was comparable across the 2 groups $(\mathrm{p}=0.697)$ [17].

The TPT theoretically should increase with increased polyp detection with EC, CAC and ERC. Data do support the expected trend in case of EC and ERC but with CAC, the TPT seems to be shortened in comparison to SC, may be secondary to shortened CIT.

\section{Outcomes}

$\mathrm{ADR}$ is one of the quality indicator for colonoscopies. It is a measurement of all patients in whom at least 1 adenoma was detected during the colonoscopy. Increase in ADR is expected to decrease the risk of interval CRC. Table 1 details the various outcomes across all the studies including polyp detection rate (PDR), ADR, polyp morphology, size and distribution.

\section{Polyp Detection Rate}

PDR represents the number of patient in whom at least 1 polyp was detected. PDR was found to be significantly higher at $55.4 \%$ for the EC group of the study by Floer et al. [7] as compared to $38.4 \%$ in the SC group ( $<<0.0001$ ). Similarly, Biecker et al. [8] demonstrated a higher PDR for the EC group (56\%) compared to $42 \%$ for the SC group $(\mathrm{p}<0.04)$.

Contrary to expectation, Frieling et al. [10] reported a lower PDR (31.8\%) for the CAC group in comparison to the CC group (39.3\%; p > 0.05). Total number of polyps detected in CAC group of study by de Wijkerslooth et al. [12] were 682 versus 665 in the CC group ( $p=0.71)$. In the study conducted by Park et al. [14] subjects were enrolled after having undergone a $\mathrm{RC}$ and been reported to have an unresectable polyp by the standard forceps. They were then randomized into either CAC arm or repeat RC. The mean number of polyps found in the CAC arm were $3.4 \pm 2.7$, higher than that in the $\mathrm{RC}$ arm $(2.7 \pm$ $1.9 ; \mathrm{p}=0.003)$. The mean number of missed polyps were 
also higher in the CAC group at $1.1 \pm 1.5$ versus $0.8 \pm 0.9$ for RC group $(p=0.024)$. The missed polyps difference between the 2 groups was much more significant in patients with 3 or more polyps detected on the initial examination. Based on these findings, authors concluded that CAC demonstrated an increase in the number of polyps detected over RC and would prove to be useful to lower the missed polyp number in patients with 2 or more polyps on initial examination [14]. In another study, a minimal increase in PDR was seen for the CAC group $(32.8 \%)$ versus $31.3 \%$ for the SC group $(\mathrm{p}=0.24)$ [15].

In the CLEVER study, author grouped subjects into 2 arms. ERC arm received ERC first followed by SC and vice versa for the other (SC) arm. Polyp miss rate for first arm was $9.1 \%$, almost one-fifth of that for the second arm $(52.8 \% ; \mathrm{p}<0.001)$ [17].

There is good uniform evidence for increased PDR with EC and ERC $[7,8,17]$. From 5 studies with available data for PDR for CAC, 1 study showed statistically significant positive association [14], 2 showed positive association but lacked statistical significance $[12,15]$ and 1 showed negative association which also lacked statistical significance [10]. Overall, the evidence for increased PDR for CAC is not yet uniform.

\section{Adenoma Detection Rate}

Floer et al. [7] in their study showed an increase in the ADR for the EC group at $35.4 \%$ as compared to $20.7 \%$ in the SC group ( $\mathrm{p}<0.0001)$. Also, EC was found to be an independent factor in obtaining a higher ADR with an OR of 2.09 (CI 1.335-3.273). Similarly, a much higher ADR was found for the EC group at $36 \%$ in comparison to $28 \%$ for the SC group ( $\mathrm{p}=0.043$ ) [8].

Frieling et al. [10] reported no significant difference in the number of adenoma per patient across the 2 study arms. Lee et al. [11] showed a lower ADR for the CAC group $(30.5 \%)$ when compared to $37.5 \%$ for the RC group $(\mathrm{p}=0.018)$. The CAC group in this study had a high proportion of poor bowel prep (13.8\%) compared to SC group $(9.6 \%)$, which could have biased the final results $(p=0.006)$ [11]. ADR for both groups (CAC and CC) in the prospective study by de Wijkerslooth et al. [12] was similar (28\%). In another study, ADR for the CAC group $(69 \%)$ was higher than that for SC group $(56 \% ; \mathrm{p}=0.009)$ [13].

In the CLEVER study, subjects were categorized into 2 arms. ERC arm received ERC first followed by SC and vice versa for the other (SC) arm. Adenoma miss rate for first arm was $10.4 \%$, almost one-fifth of that for the sec- ond $\operatorname{arm}(48.3 \% ; \mathrm{p}<0.001)$ [17]. ADR for the first arm after ERC was $49.1 \%$ compared to $28.8 \%$ for the other arm $(\mathrm{p}=0.025)$.

There is strong evidence for increased ADR with EC and ERC $[7,8,17]$. The association between ADR and CAC as compared to SC seems to be non-uniform with conflicting evidence. Two studies reported almost comparable ADR across the study arms $[10,12]$ and the other 2 studies showed statistical significant differences in ADR but in opposite directions $[11,13]$. At this juncture, the evidence is not enough to come to a conclusion regarding the efficacy of CAC in improving ADR when compared to SC.

\section{Polyp Size and Distribution}

Floer et al. [7] in their study showed a higher percentage of polyps $(\geq 1 \mathrm{~cm})$ detected by the EC $(12.8 \%)$ in comparison to SC group (9\%; $\mathrm{p}=0.005)$. The absolute number of polyps $(<1 \mathrm{~cm})$ detected, were also higher in the EC group at 272 versus 172 in the SC group ( $p<$ $0.0001)$. The sigmoid PDR for EC group $(30.1 \%)$ was almost twice that of SC group (17.3\%; $p=0.001)$ [7]. Similarly, the absolute number of sigmoid polyps $(<1 \mathrm{~cm})$ detected by EC (108) were 2 times that of SC group (52; $\mathrm{p}=0.001$ ) [7]. In the study by Biecker et al. [8], PDR for sigmoid colon in the EC group (32\%) was more than double of SC group (15\%; p < 0.0001). EC group also demonstrated a significantly higher PDR for cecum (14 vs. $7 \%$ detected by SC; $\mathrm{p}=0.019$ ). Among the sigmoid and cecum polyps, there was a much higher detection of polyps $<1 \mathrm{~cm}$ in size by EC (120 sigmoid and 37 cecum polyps vs. 42 sigmoid $(\mathrm{p}=0.001)$ and 14 cecum polyps $(\mathrm{p}=0.002$ by $\mathrm{SC}))[8]$.

Frieling et al. [10] were unable to demonstrate any statistically significant difference in the size or distribution of detected polyps across CAC or CC groups. ADR for $<6$, 6-9 or $>10 \mathrm{~mm}$ size polyps was comparable between CAC and CC groups in the study by de Wijkerslooth et al. [12]. The author did show a higher mean number of advanced adenoma per patient for proximal colon (proximal to splenic flexure) in the CAC group compared to CC group $(\mathrm{p}=0.07)$. Rastogi et al. [13] showed that of all the detected adenomas, the majority were $<5 \mathrm{~mm}$ in size and the difference between CAC (321 of 474) and SC groups (204 of 298) was significant $(\mathrm{p}<0.001)$. Number of right-sided adenomas detected were also higher for CAC group (278 of 474) in comparison to SC group (169 of 298; $\mathrm{p}=0.003$ ) [13]. There were no significant differences reported in the distribution or size of missed polyps across the CAC and RC study arm [14]. Tee et al. [15] also showed a higher 
absolute number for polyps $(\leq 5 \mathrm{~mm})$ in the CAC group (121 of 147) versus SC (84 of 107; $p=0.59$ ).

The CLEVER study results for ERC showed a lower rate of missed polyps for both proximal and distal colon when compared to SC $(\mathrm{p}<0.001)$ [17]. Among the misses polyps, the majority were $1-5 \mathrm{~mm}$ in size $(10.7 \%$ for ERC compared to $57.6 \%$ for SC, $\mathrm{p}<0.001$ ) [17].

EC and ERC seems to improve detection of polyps located in proximal colon and those with size $<1 \mathrm{~cm}$. In the CLEVER study, the use of ERC after SC changed the recommended surveillance interval in 11 of 59 subjects as compared to the other arm ( 2 of $57 ; \mathrm{p}=$ 0.013). For CAC, few studies did show improvement in PDR for right colon [13] and small polyps $(<5 \mathrm{~mm})$ $[13,15]$ but the trends were not uniform across other studies $[10,12,14]$. With the potential for higher rate of detection of proximal colon lesions with EC, CAC and ERC, their potential in reducing the risk of interval cancers should not be overlooked but requires more evidence.

\section{Polyp Morphology and Histology}

Majority of the polyps detected in the study by Floer et al. [7] were sessile across both study arms but EC (80.1\%) detected more than SC $(76.7 \%$; $<0.0001)$ Number of low-grade intraepithelial neoplasm (LGIN) adenomas in the CAC group (137) were higher than in SC group (87; $\mathrm{p}=0.002)$ [7]. Similarly, the median number of LGIN adenoma per patient for EC group (2) was greater than for the SC group ( $1 ; \mathrm{p}=0.001)$ [8]. There were no considerable differences in the detection of high grade intraepithelial neoplasm (HGIN) adenoma or carcinoma by EC or SC in either study $[7,8]$.

There was no statistically significant difference for detected polyp histology (adenoma or advanced adeno$\mathrm{ma}$ ) across CAC and SC/RC/CC study arms [10-12, 15]. Rastogi et al. [13] reported detection of 103 flat adenomas (flat ADR 24\%) by CAC versus 35 (flat ADR 10\%) by SC ( $\mathrm{p}<0.001)$. Also, a higher absolute number of advanced adenomas were detected in the CAC study arm (79) compared to SC (39), but lacked statistical significance.

In the CLEVER study, the ERC missed fewer flat polyps $(\mathrm{p}=0.003)$, sessile polyps $(\mathrm{p}<0.001)$, hyperplastic $(\mathrm{p}<0.001)$ and adenomatous polyps $(\mathrm{p}<0.001)$ compared to SC.

$\mathrm{EC}, \mathrm{CAC}$ and ERC have better outcomes in detection of sessile and flat polyps but the evidence is not sufficient yet. EC and CAC failed to show any improvement in detection of HGIN or carcinoma in above studies.

Cuffs, Caps and Rings in Enhancing

Colonoscopy Outcome
Difficulty or Discomfort during Colonoscopy

Lee et al. [11] in their study reported difficulty score for subjects undergoing colonoscopy. CAC study arm had a lower score $(2.5 \pm 2.4)$ as compared to the RC arm $(2.9 \pm 2.6)$. This, however, could also demonstrate a bias on the part of the endoscopists since blinding with regards to the type of colonoscope being used was not done. Pain score and difficulty of polypectomy was not significantly different in the 2 groups. de Wijkerslooth et al. [12] used the Gloucher Comfort Scale for scoring discomfort during the procedure. They reported a low score for CAC group $2.0 \pm 1.0$ suggesting less discomfort as compared to those receiving the $\mathrm{CC}$ with a score of $2.2 \pm 1.0$. However, the perceived burden questionnaire done 2 weeks post procedure nullified this difference between the 2 groups. The pain score for women after 2 weeks of the procedure still demonstrated less pain scores for CAC at $1.7 \pm 1.1$ in comparison to $1.9 \pm 1.3$ for RC. No such data is available for EC or ERC.

A shorter CIT could be a plausible reason for lower difficulty score and pain score with CAC.

\section{Adverse Events}

$\mathrm{SC}$ is associated with rare complications like perforation, etc. Addition of a device like transparent cap, cuff or rings to the colonoscope raises concern for added adverse events. The most common reported complications are minor mucosal lacerations. In situ loss of cuff/cap/ring from the device is another plausible adverse event with EC, CAC or ERC.

\section{Minor Mucosal Lacerations}

Floer et al. [7] reported 18 (7.3\%) cases within the EC group to have had minor mucosal lacerations as compared to $2(0.8 \%)$ cases with SC. The reported events did not have any clinical impact. Nine of 245 (4\%) cases in the EC group of Biecker et al. [8] had reported minor mucosal lacerations versus 2 of 253 (1\%) cases in the SC group of the study. Thirty percent cases in the retrospective study by Lenze et al. [9] had mucosal erosions with EC use. These minor mucosal erosions and lacerations could be attributed to the EC. No such events were reported for CAC or ERC [10-17].

\section{Loss of Cuff, Cap or Rings}

Biecker et al. [8] reported 6 of 245 cases (2.5\%) where there was loss of cuff. All the cases of detachment occurred during the procedure with the EC-590 WL4 and $\mathrm{WN} 4$ endoscopes. There was no loss of cuff in other $2 \mathrm{EC}$ studies $[7,9]$. A tight fitting cuff to the tip of the endo- 
scope can potentially avoid loss of cuff during the procedure. It is unclear if the particular endoscope used by Biecker et al. [8] study was the cause or not. No such events were reported for cap or rings in CAC or ERC procedures respectively [10-17].

\section{Perforation}

One case of perforation occurred in the SC group of Biecker et al. [8], which was attributed to the complex cecum mucosectomy. One perforation event also occurred in the CC group of de Wijkerslooth et al. [12] study. One fatal colonic perforation was reported in a 73-year-old patient, $12 \mathrm{~h}$ after prolonged $\mathrm{RC}$ and CAC in the study by Lee et al. [16]. Due to the patient's poor premorbid condition, surgery was not carried out. No such event was reported for ERC [17].

\section{Post Polypectomy Bleeding}

A case of post-polypectomy bleeding was reported in both study arms of Tee et al. [15] and in the CC group of de Wijkerslooth et al. [12] study. All cases were managed conservatively with good outcome.

\section{Miscellaneous}

Hypoxia was reported in 29 cases in the CAC arm of Lee et al. [11] as compared with 11 cases in RC. All hypoxic events were transient and no procedure was terminated. Patients responded to short period of supplemental oxygen. In the same study group 1 patient from the $\mathrm{RC}$ group required hospitalization. de Wijkerslooth et al. [12] reported a case of spinal epidural abscess (23 days post CC) and was unrelated to the procedure as per the author. The same study also reported 3 non-colonoscopy-related complications in the subjects undergoing CAC: pneumonia, urinary tract infection and atrial fibrillation.

$\mathrm{EC}, \mathrm{CAC}$ and ERC are all pretty safe procedures, comparable to SC. In most cases, the complications were minor and were managed without any major interventions with good outcomes. Summary of adverse events has been detailed in table 1 .

\section{Summary and Future Directions}

CRC is a common cause of cancer-related death. By improving the detection of precursor lesions in the adenoma-carcinoma sequence, mortality from CRC can be reduced. Use of colonoscope with cap, cuff or rings attached to its distal tip has been shown to increase the $\mathrm{PDR}$ and $\mathrm{ADR}$, predominantly for the small polyps $(<1$ $\mathrm{cm}$ ) and proximal colon location. Evidence is uniform for EC and ERC but not for CAC. Benefits of shorter CIT, improved cecum intubation rates and decreased pain scores during colonoscopy done with assistance of cuff or cap has the potential to decrease the number of incomplete colonoscopy and increase overall patient satisfaction, thus improving follow-up. More evidence for the impact of EC, CAC and ERC on clinical outcomes like change in recommended surveillance intervals and detection of high-grade dysplastic lesions/advanced adeno$\mathrm{ma}$ is needed before a change in current practices is made. Large multicentric prospective studies with headto-head comparison between EC, CAC, ERC and SC are awaited.

\section{Disclosure Statement}

None of the authors have any conflicts of interest or financial relationship with the company that produces or distributes the device described in the review article.

\section{Source of Funds}

No grant or funding source was involved in writing up the review article.

\section{Author Contribution}

Dr. D. Jain contributed to literature review, acquisition of data, interpretation of data and drafting of the manuscript. Dr. N. Sandhu contributed to acquisition of data and drafting of the manuscript. Dr. S. Singhal contributed to literature review and critical revision of the manuscript for important intellectual content.

\section{References}

1 SEER Stat Facts Sheets: Colon and Rectum Cancer. seer.cancer.gov/statfacts/html/ colorect.html (accessed December 9, 2015).

2 Atkin WS, Edwards R, Kralj-Hans I, Wooldrage K, Hart AR, Northover JM, Parkin DM, Wardle J, Duffy SW, Cuzick J; UK Flexible Sigmoidoscopy Trial Investigators: Once-only flexible sigmoidoscopy screening in prevention of colorectal cancer: a multicentre randomised controlled trial. Lancet 2010; 375:1624-1633.

3 Kohler BA, Ward E, McCarthy BJ, Schymura MJ, Ries LA, Eheman C, Jemal A, Anderson RN, Ajani UA, Edwards BK: Annual report to the nation on the status of cancer, 1975-2006, featuring tumors of the brain and other nervous system. J Natl Cancer Inst 2011;103:714736. 
4 Nishihara R, Wu K, Lochhead P, Morikawa T, Liao X, Qian ZR, Inamura K, Kim SA, Kuchiba A, Yamauchi M, Imamura Y, Willett WC, Rosner BA, Fuchs CS, Giovannucci E, Ogino S, Chan AT: Long-term colorectal-cancer incidence and mortality after lower endoscopy. N Engl J Med 2013;369:1095-1105.

5 Zauber AG, Winawer SJ, O’Brien MJ, Lansdorp-Vogelaar I, Van Ballegooijen M, Hankey BF, Shi W, Bond JH, Schapiro M, Panish JF, Stewart ET, Waye JD: Colonoscopic polypectomy and long-term prevention of colorectal-cancer deaths. N Engl J Med 2012; 366:687-696.

6 Kaminski MF, Regula J, Kraszewska E, Polkowski M, Wojciechowska U, Didkowska J, Zwierko M, Rupinski M, Nowacki MP, Butruk E: Quality indicators for colonoscopy and the risk of interval cancer. $\mathrm{N}$ Engl J Med 2010;362:1795-1803.

7 Floer M, Biecker E, Fitzlaff R, Röming H, Ameis D, Heinecke A, Kunsch S, Ellenrieder V, Ströbel P, Schepke M, Meister T: Higher adenoma detection rates with endocuff-assisted colonoscopy - a randomized controlled multicenter trial. PLoS One 2014;9:e114267.
8 Biecker E, Floer M, Heinecke A, Ströbel P, Böhme R, Schepke M, Meister T: Novel endocuff-assisted colonoscopy significantly increases the polyp detection rate: a randomized controlled trial. J Clin Gastroenterol 2015;49: 413-418.

9 Lenze F, Beyna T, Lenz P, Heinzow HS, Hengst K, Ullerich H: Endocuff-assisted colonoscopy: a new accessory to improve adenoma detection rate? Technical aspects and first clinical experiences. Endoscopy 2014;46:610614.

10 Frieling T, Neuhaus F, Kuhlbusch-Zicklam R, Heise J, Kreysel C, Hülsdonk A, Blank M, Czypull M: Prospective and randomized study to evaluate the clinical impact of cap assisted colonoscopy (CAC). Z Gastroenterol 2013;51:1383-1388.

11 Lee YT, Lai LH, Hui AJ, Wong VW, Ching JY, Wong GL, Wu JC, Chan HL, Leung WK, Lau JY, Sung JJ, Chan FK: Efficacy of cap-assisted colonoscopy in comparison with regular colonoscopy: a randomized controlled trial. Am J Gastroenterol 2009;104:41-46.

12 de Wijkerslooth TR, Stoop EM, Bossuyt PM, Mathus-Vliegen EM, Dees J, Tytgat KM, van Leerdam ME, Fockens P, Kuipers EJ, Dekker E: Adenoma detection with cap-assisted colonoscopy versus regular colonoscopy: a randomised controlled trial. Gut 2012;61:1426-1434.
13 Rastogi A, Bansal A, Rao DS, Gupta N, Wani SB, Shipe T, Gaddam S, Singh V, Sharma P: Higher adenoma detection rates with cap-assisted colonoscopy: a randomised controlled trial. Gut 2012;61:402-408.

14 Park SY, Kim HS, Yoon KW, Cho SB, Lee WS, Park CH, Joo YE, Choi SK, Rew JS: Usefulness of cap-assisted colonoscopy during colonoscopic EMR: a randomized, controlled trial. Gastrointest Endosc 2011;74:869-875.

15 Tee HP, Corte C, Al-Ghamdi H, Prakoso E, Darke J, Chettiar R, Rahman W, Davison S, Griffin SP, Selby WS, Kaffes AJ: Prospective randomized controlled trial evaluating capassisted colonoscopy vs standard colonoscopy. World J Gastroenterol 2010;16:39053910.

16 Lee YT, Hui AJ, Wong VW, Hung LC, Sung JJ: Improved colonoscopy success rate with a distally attached mucosectomy cap. Endoscopy 2006;38:739-742.

17 Dik VK, Gralnek IM, Segol O, et al: Multicenter, randomized, tandem evaluation of EndoRings colonoscopy - results of the CLEVER study. Endoscopy 2015;47:11511158 . 